\title{
Rheology and Phase Behavior of Carbon Dioxide
}

\section{and Crude Oil Mixtures}

Ruien Hu, John P. Crawshaw, J. P. Martin Trusler, and Edo S. Boek

Qatar Carbonate and Carbon Storage Research Centre (QCCSRC), Department of Chemical Engineering, Imperial College London, South Kensington Campus, London SW7 2AZ, United Kingdom

\section{KEYWORDS}

Rheology, phase behavior, heavy crude oil, carbon dioxide, viscosity, non-Newtonian fluid

\section{ABSTRACT}

The rheology of Zuata heavy crude oil, saturated with carbon dioxide, was studied at a temperature of $50{ }^{\circ} \mathrm{C}$ and pressures up to 220 bar. Observations of phase behavior were also reported and used to interpret the rheological data. The crude oil is very viscous and non-Newtonian at ambient pressure, but when brought into equilibrium with $\mathrm{CO}_{2}$ the non-Newtonian behavior was weakened and eventually disappeared at high $\mathrm{CO}_{2}$ pressures. When diluted with $10 \mathrm{wt} \%$ and $30 \mathrm{wt} \%$ toluene, the diluted crude oils and their mixtures with $\mathrm{CO}_{2}$ behaved as Newtonian fluids. The $\mathrm{CO}_{2}$ saturated mixture of the crude oil samples showed an exponential decrease in viscosity with increasing $\mathrm{CO}_{2}$ pressure, but an increase in viscosity at higher pressures. Observing through a view cell, the $\mathrm{CO}_{2}$ dissolution caused a swelling effect on the original crude. When saturated with $\mathrm{CO}_{2}$, the swelling effect also occurred on the $10 \mathrm{wt} \%$ diluted crude oil, but the volume of the oil rich phase was 
decreased at higher pressures. However, for the $30 \mathrm{wt} \%$ diluted crude oil, a second liquid phase was observed on top of the oil rich phase, at pressures higher than the $\mathrm{CO}_{2}$ critical point. The mixture viscosity was inversely proportional to the $\mathrm{CO}_{2}$ solubility.

\section{INTRODUCTION}

Carbon dioxide $\left(\mathrm{CO}_{2}\right)$ released by the massive consumption of fossil fuels contributes significantly to global warming and extreme weather. As one of the final products of burning hydrocarbon fuels, its high stability and considerable concentration in the Earth's atmosphere makes $\mathrm{CO}_{2}$ one of most important greenhouse gases. The surplus of $\mathrm{CO}_{2}$ is caused by our extensive use of fossil fuels, which emits huge amounts of $\mathrm{CO}_{2}$ into the atmosphere and deforestation, which reduces the number of trees that absorb $\mathrm{CO}_{2}$ during photosynthesis [1]. Immediate actions are required to control $\mathrm{CO}_{2}$ emission, in order to prevent us from losing our security and prosperity by extensive climate change.

To reduce the $\mathrm{CO}_{2}$ emission, a range of solutions based on different principles has been proposed, including carbon capture and storage (CCS). CCS is a family of technologies and techniques that enable the capture of $\mathrm{CO}_{2}$ from power stations or other industrial processes, the transport of $\mathrm{CO}_{2}$ via ships or pipelines, and its storage underground, in depleted oil and gas fields and deep saline formations [2]. However, consideration of economic feasibility leads to an alternative to CCS: carbon capture, utilization and storage (CCUS). This is a process to turn the waste $\mathrm{CO}_{2}$ into valuable products such as chemicals and fuels, while at the same time contributing to climate change mitigation [3].

$\mathrm{CO}_{2}$ flooding of oil reservoirs is considered to be one of the most important elements in CCUS, because it provides an approach to extract additional crude oil while storing some $\mathrm{CO}_{2}$. It is well 
known that carbon dioxide can significantly reduce crude oil viscosity and increase the oil swelling factor, which play an important role in $\mathrm{CO}_{2}$ flooding [4]. There are many studies in the literature on the viscosity and phase behavior of $\mathrm{CO}_{2}$ and heavy crude oil mixtures. Traditionally, the focus of such studies is on how the physical properties measured are related to each other and to the operation conditions. An example is Chuang et al., where the $\mathrm{CO}_{2}$ solubility, oil swelling factor and viscosity for 4 different $\mathrm{CO}_{2}$ saturated heavy crude oils were measured and correlated at different temperatures and pressures [4]. Similar studies can also be found in [5-11]. In addition, the viscosity of $\mathrm{CO}_{2}$ and alkane diluted crude oil was reported by Li et al. [12].

Numerous papers report the phase behavior of $\mathrm{CO}_{2}$ and crude oil mixtures. Similar to the mixture of $\mathrm{CO}_{2}$ with alkanes, $\mathrm{CO}_{2}$ and crude oil mixtures show liquid-liquid or liquid-liquid-vapor equilibria at temperatures and pressures lower than the $\mathrm{CO}_{2}$-crude oil minimum miscibility point. The phase boundaries are determined by the crude oil composition, since $\mathrm{CO}_{2}$ extracts the light and intermediate components in the crude oil to generate a second liquid phase on top of the oil rich phase $[13,14]$.

Moreover, as reported by many papers [6-9, 15], $\mathrm{CO}_{2}$ solubility in crude oil normally increases with increasing pressure but decreases with increasing temperature. The pressure sensitivity of the $\mathrm{CO}_{2}$ solubility at high pressures depends on the phase of $\mathrm{CO}_{2}$ : when $\mathrm{CO}_{2}$ is in the liquid phase, the solubility is least sensitive to pressure [4, 7]. On the other hand, there are two determining factors on crude oil density: the compression effect of pressure and the swelling effect of dissolved $\mathrm{CO}_{2}$ $[4,6,7,9]$. Therefore, the crude oil density changes resulting from changes in $\mathrm{CO}_{2}$ pressure depend on the nature of the crude oil and the operational conditions. 
In all the studies mentioned above, except for the work of Sayegh et al., the viscosity was measured by a viscometer, indicating that the shear rate or shear stress applied to the mixture was constant. Although Sayegh et al. measured the viscosity at more than two flow rates using a capillary viscometer, the tested crude oil mixture with $\mathrm{CO}_{2}$ was found to be Newtonian [6]. A review by Kariznovi et al. about the experimental apparatus used to study the phase behavior of solvent and heavy crude oil mixtures also shows that the viscosity response to changes in shear rate is normally ignored in the study of $\mathrm{CO}_{2}$ and crude oil mixtures [16]. However, it is well known that heavy crude oil can exhibit non-Newtonian behavior because of the structured network formed by macromolecules, such as asphaltene [17]. Although a numbers of studies report how the heavy crude oil viscosity responds to shear rate [18-24], only a few address $\mathrm{CO}_{2}$ and heavy crude oil mixtures. To our best knowledge, only the work by Behzadfar et al. reported the rheology measurement of the mixture of $\mathrm{CO}_{2}$ and a bitumen [25].

In this paper, the viscosity of the $\mathrm{CO}_{2}$ and crude oil mixture is visited from a rheological point of view, adding shear rate as another variable so that non-Newtonian behavior can be observed. Phase behavior measurements were also performed to aid interpretation of the complex viscosity response to added $\mathrm{CO}_{2}$.

\section{EXPERIMENTAL SECTION}

\section{Materials}

The oil (supplied by Shell) studied is a heavy crude oil from the Zuata field in Venezuela. The basic properties of the heavy crude oil can be found elsewhere [26]. In addition to the original heavy crude oil, two samples of the crude diluted with toluene were studied. The toluene used was 
sourced from Sigma-Aldrich with a purity of 99.8\%. The crude oil and toluene were used without further treatment. The compositions of the diluted crude oil samples are shown in Table 4 .

\section{Measurement Equipment}

The rheology measurements were performed using a high pressure circulation system built in this project, as shown in Figure 1. Although a detailed description of the circulation system and its operation can be found in our previous paper [26], a brief description of the experimental procedure is given here. The crude oil sample was first loaded into the mixer, and the whole circulation system primed with the crude oil sample. After the system was heated up to the desired temperature, $\mathrm{CO}_{2}$ was injected into the mixer using the syringe pump. The pressure set point was then input into the syringe pump that controlled the system pressure through the $\mathrm{CO}_{2}$. When the $\mathrm{CO}_{2}$ pressure was steady, both the stirrer and gear pump were turned on. At each pressure level, both stirring and circulation were continued until equilibrium $\mathrm{CO}_{2}$ saturation was reached, indicated by no further change in the pump volume. At equilibrium, the stirrer and gear pump were turned off and the rheology measurement was performed in the rheometer. The $\mathrm{CO}_{2}$ and crude oil equilibrium was confirmed at each pressure by repeating the cycle of circulation for several hours followed by rheology measurements until no further changes in viscosity were observed.

One modification from the previously reported apparatus has been made; a more powerful gear pump was introduced to handle the heavy crude oil. The new gear pump, equipped with hardened steel gears, is a chemical industrial pump from Polymer Systems Inc. (PSI), model number CIP12/1.5. The gear pump can be operated up to 345 bar and $454{ }^{\circ} \mathrm{C}$, and provides a maximum differential pressure $(\Delta P)$ of 69 bar. Such $\Delta P$ is high enough to circulate the heavy crude oil in the system. 
Furthermore, two rheometer pressure cells were used in this work, both from Anton Paar. One has a coaxial cylinder geometry (model no. CC29/Pr) designed for high viscosity fluids, while the other one has a double gap geometry (model no DG35.12/Pr) for low viscosity fluids. The coaxial cylinder geometry was tested with viscosity standard oil S600 from Paragon Scientific Ltd (with viscosity of $1260 \mathrm{mPa} \cdot \mathrm{s}$ at $25{ }^{\circ} \mathrm{C}$ ), and the maximum measurement error was found to be $3 \%$. On the other hand, the rheometer with double gap geometry was tested with viscosity stand oil N100 from Paragon Scientific Ltd (with viscosity of $200 \mathrm{mPa} \cdot \mathrm{s}$ at $25{ }^{\circ} \mathrm{C}$ ), and the maximum measurement error was 5\%.

In addition, a separate view cell system was built to measure the phase behavior of the crude oil and $\mathrm{CO}_{2}$ mixture in the range of conditions used in the rheology measurements. The view cell (VC-series from CORE LAB) was placed in an oven, as shown in Figure 2. The view cell contains two opposed glass windows, between which there is a $4.491 \times 2.527 \times 8.811 \mathrm{~cm}$ chamber where the tested fluid could be observed optically. To rapidly reach equilibrium, the cell was equipped with a magnetic stirrer coupled to a rotating magnet driven by an electric motor. By mounting a light source to one side and a SLR camera with a borescope to the other side of the cell, the fluid can be observed and photographed and thus the phase behavior information can be recorded. In a typical experiment the crude oil was first loaded into the view cell, and the remaining volume in the system evacuated for 15 minutes to remove air. The system temperature was brought to the desired value by the oven and $\mathrm{CO}_{2}$ was then introduced to the view cell through the syringe pump at the desired pressure. When the pressure stabilized, usually in less than 10 minutes, the stirrer was turned on. The stirring time at each pressure level was more than 24 hours; the equilibrium saturation of the crude oil with $\mathrm{CO}_{2}$ was confirmed by continuing measurements of the pump 
volume until no further changes were observed. When the equilibrium was reached, the stirrer was turned off and the position of the interface after settling was recorded using the SLR camera.

Theoretically, density and solubility can be measured through the view cell. A certain amount $\left(m_{\text {oil, }}\right)$ of the crude oil sample is loaded into the view cell. From a scale placed in front of the view cell window, the height of the oil phase can be measured. Knowing the internal dimensions of the sample chamber of the view cell, the volume of the oil phase, $V_{\text {oil, }, 1}$, and the volume above the oil phase, which is occupied by $\mathrm{CO}_{2}, V_{\mathrm{CO} 2,1}$, can be worked out. The total mass of $\mathrm{CO}_{2}$ injected in the view cell, $m_{\mathrm{CO} 2,1}$, including both the $\mathrm{CO}_{2}$ dissolved into the oil and that occupying the volume above the oil phase, can be measured through the volume change in the syringe pump. The total mass balance in the view cell is

$$
m_{\text {oil }, 1}+m_{\mathrm{CO} 2,1}=\rho_{\text {oil }} V_{\text {oil, } 1}+\rho_{\mathrm{CO} 2} V_{\mathrm{CO} 2,1}
$$

where $\rho_{\text {oil }}$ and $\rho_{\mathrm{CO} 2}$ are the density of oil rich phase and $\mathrm{CO}_{2}$ rich phase, respectively. The mass balance of $\mathrm{CO}_{2}$ is given by

$$
m_{\mathrm{CO} 2,1}=w_{\mathrm{CO} 2}^{\text {oil }} \rho_{\text {oil }} V_{\text {oil }, 1}+w_{\mathrm{CO} 2}^{\mathrm{CO} 2} \rho_{\mathrm{CO} 2} V_{\mathrm{CO} 2,1}
$$

where $w_{\mathrm{CO} 2}^{\text {oil }}$ and $w_{\mathrm{CO} 2}^{\mathrm{CO} 2}$ are the mass compositions of $\mathrm{CO}_{2}$ in the oil rich phase and $\mathrm{CO}_{2}$ rich phase respectively. If the experiment is then repeated with a different loading of crude oil, $m_{\mathrm{oil}, 2}$ then we have

$$
\begin{gathered}
m_{\mathrm{oil}, 2}+m_{\mathrm{CO} 2,2}=\rho_{\mathrm{oil}} V_{\mathrm{oil}, 2}+\rho_{\mathrm{CO} 2} V_{\mathrm{CO} 2,2} \\
m_{\mathrm{CO} 2,2}=w_{\mathrm{CO} 2}^{\mathrm{oil}} \rho_{\mathrm{oil}} V_{\mathrm{oil}, 2}+w_{\mathrm{CO} 2}^{\mathrm{CO} 2} \rho_{\mathrm{CO} 2} V_{\mathrm{CO} 2,2}
\end{gathered}
$$


As long as the temperature and pressure are the same for both experiments, for a given crude oil sample the densities in Equation (1) and (3), and mass compositions in Equation (2) and (4) are the same. Therefore, solving these two systems of equations can provide the values of the density and the $\mathrm{CO}_{2}$ composition of each phase.

However, the accuracy of the above method is very sensitive to the accuracy of the volume measurement. To illustrate this, given that the total mass in the view cell is $m_{\mathrm{T}, 1}=m_{\mathrm{oil}, 1}+m_{\mathrm{CO} 2,1}$ and $m_{\mathrm{T}, 2}=m_{\mathrm{oil}, 2}+m_{\mathrm{CO} 2,2}$, solving Equation (1) and (3) leads to

$$
\rho_{\mathrm{CO2} 2}=\frac{m_{\mathrm{T}, 2} V_{\mathrm{oil}, 1}-m_{\mathrm{T}, 1} V_{\mathrm{oil}, 2}}{V_{\mathrm{oill}, 1} V_{\mathrm{CO} 2,2}-V_{\mathrm{CO} 2.1} V_{\mathrm{oil}, 2}}
$$

Knowing that the total volume of the view cell is a constant $V_{\mathrm{T}}$, and $V_{\mathrm{T}}=V_{\text {oil, } 1}+V_{\mathrm{CO} 2,1}=V_{\text {oil,2 }}+$ $V_{\mathrm{CO}, 2,}$, Equation (5) can be reduced to

$$
\rho_{\mathrm{CO} 2}=\frac{m_{\mathrm{T}, 2} V_{\mathrm{oil}, 1}-m_{\mathrm{T}, 1} V_{\mathrm{oil}, 2}}{V_{\mathrm{T}}\left(V_{\mathrm{oil}, 1}-V_{\mathrm{oil}, 2}\right)}
$$

Given that mass measurement is reasonably accurate and the focus here is the effect of the volume measurement, the mass is treated as a constant. Then the standard deviation of $\rho_{\mathrm{CO}}, \sigma_{\rho}$, can be approximated by the propagation of errors formula [27]:

$$
\sigma_{\rho}^{2} \approx\left[\frac{\partial \rho_{\mathrm{CO} 2}}{\partial V_{\text {oil }, 1}}\right]^{2} \sigma_{\mathrm{V} 1}^{2}+\left[\frac{\partial \rho_{\mathrm{CO} 2}}{\partial V_{\text {oil, }, 2}}\right]^{2} \sigma_{\mathrm{V} 2}^{2}+2\left[\frac{\partial \rho_{\mathrm{CO} 2}}{\partial V_{\text {oil, } 1}} \cdot \frac{\partial \rho_{\mathrm{CO} 2}}{\partial V_{\text {oil }, 2}}\right] \sigma_{\mathrm{V} 1, \mathrm{~V} 2}
$$

where $\sigma_{\mathrm{V} i}$ is the standard deviation of $V_{\text {oil, }, i}$ and $\sigma_{\mathrm{V} 1, \mathrm{~V} 2}$ the covariance between $V_{\mathrm{oil}, 1}$ and $V_{\mathrm{oil}, 2 .}$. Given that the errors in measurement of $V_{\text {oil,1 }}$ and $V_{\text {oil,2 }}$ are independent, $\sigma_{\mathrm{V} 1, \mathrm{~V} 2}=0$, Equation (7) is simplified to 


$$
\sigma_{\rho}^{2} \approx\left[\frac{\partial \rho_{\mathrm{CO} 2}}{\partial V_{\mathrm{oil}, 1}}\right]^{2} \sigma_{\mathrm{V} 1}^{2}+\left[\frac{\partial \rho_{\mathrm{CO} 2}}{\partial V_{\mathrm{oil}, 2}}\right]^{2} \sigma_{\mathrm{V} 2}^{2}
$$

The measurement of the oil volume is done by reading the height of the oil phase, $h_{i}$, and then multiplying the dimension of the view cell chamber. So $V_{\text {oil, } I}=W \times L \times h_{I}$ where $W$ and $L$ are the constant width and length of the view cell chamber, respectively, and the subscript $i$ is for different oil loading. The standard deviation of $V_{\text {oil, } i}$ is given by:

$$
\sigma_{\mathrm{V} i}^{2}=W L \sigma_{\mathrm{hi}}^{2}
$$

where $\sigma_{\mathrm{h} i}$ is the standard deviation of $h_{\mathrm{i}}$. In our experiments we estimate $\sigma_{\mathrm{h} i}= \pm 1 \mathrm{~mm}$.

The error propagation of Equation (6) was examined using literature data. Assigning two different liquid loadings, one can calculate the total mass for two loadings using Equation (1) and (3) given the density measurements provided in literature. Then the partial differential terms in Equation (8) can be evaluated, and also the standard deviation of density in Equation (8). By comparing the calculated standard deviation $\left(\sigma_{\rho}\right)$ and the measurement value given in the literature ( $\left.\rho_{\text {literature}}\right)$, one can judge the measurement error of Equation (6) using the relative deviation, $\sigma_{\rho} / \rho_{\text {literature. }}$.

Day et al. have measured both the vapor and liquid phase densities of a $\mathrm{CO}_{2}$ and ethanol mixture at equilibrium [28], and their data was used to evaluate Equation (6). At pressures below 30 bar, the average relative deviation of vapor phase density for $\sigma_{\mathrm{h} i}= \pm 1 \mathrm{~mm}$ is $116 \%$, but if $\sigma_{\mathrm{h} i}= \pm 0.01$ $\mathrm{mm}$ it is $1.2 \%$. This means that a normal ruler cannot provide the accuracy required by Equation (6) to give an acceptable density value. Therefore this method was not directly applied in this paper, but a simplified version was used to measure the $\mathrm{CO}_{2}$ solubility as described below . 
To simplify the method, two additional assumptions have been made: (1) no crude oil components dissolve into the $\mathrm{CO}_{2}$ rich phase and thus it is pure $\mathrm{CO}_{2}$; (2) the $\mathrm{CO}_{2}$ starts to dissolve into the crude oil only after the stirrer is turned on. Assumption (2) is based on the fact that the $\mathrm{CO}_{2}$ diffusion coefficient in heavy crude oil is reasonably low [29]. The diffusion length, $2 \sqrt{ }(D t)$, is an estimate of the distance from the interface to the $\mathrm{CO}_{2}$ diffusion front [30]. In all the view cell experiments, the volume of the loaded crude oil was approximately $53 \mathrm{ml}$. The cross-sectional area of the view cell chamber, which is also the $\mathrm{CO}_{2}$ and oil contact area, $A_{\mathrm{vc}}$, is $11.35 \mathrm{~cm}^{2}$. Thus the depth of the loaded oil, $L_{\mathrm{vc}}$, is $4.47 \mathrm{~cm}$. Given that the $\mathrm{CO}_{2}$ diffusion coefficient in the oil is around $4 \times 10^{-10} \mathrm{~m}^{2} / \mathrm{s}$ [31], after about 10 minutes settling time for the syringe pump, the diffusion length is $0.069 \mathrm{~cm}$ or $2.2 \%$ of the depth of the loaded crude oil. Therefore, the amount of $\mathrm{CO}_{2}$ diffused before stirring is negligible because the diffusion length is small compared to the depth of the loaded crude oil.

According to Assumption (2) the total mass of $\mathrm{CO}_{2}$ injected into the view cell comprises the free $\mathrm{CO}_{2}$ in the space above the crude oil phase, $m_{\mathrm{CO} 2, \mathrm{f}}$ and that dissolved into the crude oil, $m_{\mathrm{CO}, \mathrm{d}}$ :

$$
m_{\mathrm{CO} 2,1}=m_{\mathrm{CO} 2, \mathrm{f}}+m_{\mathrm{CO} 2, \mathrm{~d}}
$$

With Assumption (1) $m_{\mathrm{CO} 2, \mathrm{f}}=\rho_{\mathrm{CO} 2} V_{\mathrm{CO} 2}$ and the $\mathrm{CO}_{2}$ composition is 1 , combining Equation (2) and (10) leads to

$$
m_{\mathrm{CO} 2, \mathrm{~d}}=w_{\mathrm{CO} 2}^{\mathrm{oil}} \rho_{\text {oil }} V_{\mathrm{oil}, 1}
$$

and $\rho_{\text {oil }} V_{\text {oil, } 1}$ is the mass of the oil phase so $\rho_{\text {oil }} V_{\text {oil, } 1}=m_{\mathrm{CO}, \mathrm{d}}+m_{\mathrm{oil}, 1}$. Therefore,

$$
w_{\mathrm{CO} 2}^{\mathrm{oil}}=\frac{m_{\mathrm{CO} 2, \mathrm{~d}}}{m_{\mathrm{CO} 2, \mathrm{~d}}+m_{\mathrm{oil}, 1}}
$$


It also follows from assumption (2) that, given the view cell system setup, the volume change in the syringe pump after stirring is due entirely to the $\mathrm{CO}_{2}$ dissolution into crude oil. Thus one can calculate $m_{\mathrm{CO} 2, \mathrm{~d}}$ from the volume change in the syringe pump. The measurement procedure was then the following. After loading the known amount of crude oil into the view cell, the syringe pump was set to operate in a constant pressure mode. When the pressure stabilised at the desired point, the volume in the syringe pump was marked. Next, the stirrer was turned on and the volume in the syringe pump recorded. From the volume remaining in the syringe pump when the crude oil was in equilibrium with $\mathrm{CO}_{2}$, the volume change in the syringe pump $(\Delta V)$ during stirring could be calculated. Knowing the temperature and pressure in the syringe pump, the $\mathrm{CO}_{2}$ density, $\rho_{\mathrm{CO} 2 \text {,pure, }}$ can be looked up in NIST Webbook [32]. Thus the amount of $\mathrm{CO}_{2}$ dissolved is $m_{\mathrm{CO} 2,2}=$ $\rho_{\mathrm{CO} 2 \text {,pure }} \cdot \Delta V$, and the $\mathrm{CO}_{2}$ solubility is given by Equation (12).

\section{RESULTS AND DISCUSSION}

\section{Rheological Measurements}

All experiments were conducted at $50{ }^{\circ} \mathrm{C}$ and pressures up to 220 bar. Each experiment was repeated twice and the average difference between the two independent measurements was $7 \%$.

The viscosity measurement of the original heavy crude oil and its mixture with $\mathrm{CO}_{2}$ is shown in Figure 3 and Table 1. Figure 4 illustrates the relative viscosity, which is the ratio of a given viscosity value, $\eta$, to the viscosity at the lowest shear rate, $\eta_{0}$. The dashed lines in Figure 4 represent the maximum measurement error in the test with the viscosity standard oil.

At atmospheric pressure, the heavy crude oil behaved as a non-Newtonian fluid, becoming shear thinning, as can be seen in Figure 4, at shear rates above $30 \mathrm{~s}^{-1}$. At 20 bar, when significant $\mathrm{CO}_{2}$ is dissolved into the crude oil, the Newtonian region is extended to a shear rate of $85 \mathrm{~s}^{-1}$. At higher 
shear rates the shear thinning effect can still be observed, but with a smaller gradient than at atmospheric pressure. At 40 bar, with more $\mathrm{CO}_{2}$ dissolved, the shear thinning effect is further weakened and the viscosity change is within the measurement error range. At higher pressure, the shear thinning effect completely disappeared, and the viscosity became independent of shear rate, indicating that this mixture behaved as a Newtonian fluid. As shown in Table 1, up to 120 bar the low shear rate viscosity decreased exponentially with increasing pressure, while beyond 120 bar the logarithm of viscosity increased with pressure at a gentle gradient. Similar observations can be found in [25]. Behzadfar et al. measured the rheological response of neat bitumen and $\mathrm{CO}_{2}$ bitumen mixture at different $\mathrm{CO}_{2}$ pressures. The measurement results show that the shear thinning effect of bitumen is weakened by $\mathrm{CO}_{2}$ addition [25].

The measurement results of diluted crude oil 1, containing $10 \mathrm{wt} \%$ toluene, are shown in Figure 5 and Table 2. At atmospheric pressure the viscosity of diluted crude oil 1 was $290 \mathrm{mPa} \cdot \mathrm{s}$ at $50{ }^{\circ} \mathrm{C}$. The horizontal lines in Figure 5 demonstrate that the viscosity of diluted crude oil 1 is independent of shear rate, i.e. it behaves as a Newtonian fluid at all pressures. When the pressure increases, more and more $\mathrm{CO}_{2}$ dissolves into the crude oil and reduces the mixture viscosity significantly. However, from 90 bar the crude oil viscosity starts to increase with $\mathrm{CO}_{2}$ pressure.

As illustrated in Figure 6 and Table 3, diluted crude oil 2 was a Newtonian fluid at ambient pressure. The viscosity of its mixture with $\mathrm{CO}_{2}$ was independent of shear rate, as shown by the straight line at each pressure level in Figure 6. Furthermore, similar to diluted crude oil 1, the viscosity of diluted crude oil 2 exponentially decreased with increasing $\mathrm{CO}_{2}$ pressure until 80 bar. Above 80 bar the viscosity increases with increasing pressure.

\section{Phase Behavior Measurement}


The view cell measurement, Figure 7, of the original crude oil mixed with $\mathrm{CO}_{2}$ at $50{ }^{\circ} \mathrm{C}$ shows a constant volume expansion in the oil rich phase at pressures up to 120 bar. Above 120 bar the volume of the oil rich phase continued to expand with pressure but at much a lower rate. Similar observations can be found in the study by Miller et al. [33]. They measured the swelling factor of a Wilmington heavy crude oil saturated with $\mathrm{CO}_{2}$. Their results show that the swelling factor is increased with pressure but the gradient becomes small at higher pressures. The phase behavior measurement with diluted crude oil 1 is shown in Figure 8. From 1 bar to 40 bar, although $\mathrm{CO}_{2}$ is dissolving into the diluted crude oil, the volume of the oil rich phase does not change. However, above 40 bar, the oil rich phase expands considerably with pressure up to 100 bar. Above 100 bar, the volume of the oil rich phase is shrinking slightly with increasing pressure, so that the volume at 100 bar is the maximum volume within the measured pressure arrange. Similar results were reported in [34-36]. In the Bui et al. study [34], measurements on an Arbuckle crude oil saturated with $\mathrm{CO}_{2}$ showed that the swelling factor at first increased and then decreased with increasing pressure, leading to a maximum on the swelling factor curve. In the current study, both the original heavy crude oil and diluted crude oil 1 show a correlation between the changes in oil rich phase volume and in viscosity: the trend in viscosity changes at a similar pressure to that of the oil-rich phase volume. However, the original heavy crude oil the minimum viscosity appears at 120 bar but the maximum volume at 90 bar; for diluted crude oil 1 the minimum viscosity appears at 90 bar but the maximum volume at 100 bar.

The result of the phase behavior experiment with diluted crude oil 2 is illustrated in Figure 9. As the pressure increased up to 80 bar, more and more $\mathrm{CO}_{2}$ dissolved into the crude oil phase and the crude oil phase expanded. When the pressure reached 100 bar, a second less dense liquid phase appeared. It can be seen that this second liquid phase is brown and transparent, indicating that it 
contains some light components extracted from the diluted crude oil by the supercritical $\mathrm{CO}_{2}$. At equilibrium, when the stirrer was still on, it was observed that there was a layer of oily liquid above the black crude oil rotating with the stirring, which also confirmed the existence of the second liquid phase. Similar liquid-liquid split has been seen in the experiments performed by Orr et al. [13]. In their experiments, as the $\mathrm{CO}_{2}$ pressure was increased, a second liquid phase appeared on top of the oil rich phase. Furthermore, the volume of the less dense liquid phase increased with pressure up to 160 bar. Faint banding in the images of the second liquid phase suggested that additional liquid phase may have formed. The minimum viscosity and maximum volume for diluted crude oil 2 appear at the same pressure, 80 bar.

The $\mathrm{CO}_{2}$ solubility of the crude oil samples is illustrated in Figure 10. The average difference between two independent $\mathrm{CO}_{2}$ solubility measurements was $3 \%$. The $\mathrm{CO}_{2}$ solubility increased with increasing toluene content in the crude oil samples. The solubility of diluted crude oil 2 above 80 bar was not measured, as the oil rich phase separated into two liquid phases (see Figure 9). Since $\mathrm{CO}_{2}$ is contained in all the phases, with the given setup, it is impossible to measure the split of dissolved $\mathrm{CO}_{2}$ between the liquid phases. However, this was not the case for diluted crude oil 1 and the original heavy crude oil, which remained one liquid phase over the entire pressure range accessed. The $\mathrm{CO}_{2}$ solubility in diluted crude oil 1 and the original crude oil increased exponentially with pressure from 1 bar to 100 bar. Above 100 bar, the solubility in the original crude oil increased at a smaller rate and became almost linear with pressure, while for diluted crude oil 1 the $\mathrm{CO}_{2}$ solubility above 100 bar became almost constant.

The $\mathrm{CO}_{2}$ solubility measurements with diluted crude oil 1 and the original crude oil give a further insight into the phenomenon observed through the view cell. As mentioned before, at high pressures the volume of the oil-rich phase of the original crude oil increased at a low rate with 
increasing pressure, while the volume of the oil-rich phase of diluted crude oil 1 decreased with pressure. On the other hand, at high pressures the $\mathrm{CO}_{2}$ solubility in the original crude oil increased with pressure, while that of diluted crude oil 1 showed a negligible increase. This indicates that, at high $\mathrm{CO}_{2}$ pressures, the amount of $\mathrm{CO}_{2}$ dissolved in the original crude oil was large enough to counter the compression effect, giving rise to a slight increase in the liquid level of the oil rich phase. However, the amount of $\mathrm{CO}_{2}$ dissolved in diluted crude oil 1 was too small to eliminate the compression effect, causing the shrinkage in the oil rich phase.

Furthermore, in the case of diluted crude oil 2 the extraction of the light components and the consequent formation of the second liquid phase may have caused the volume reduction in the oil rich phase. When the pressure reached 100 bar and above, an increasing proportion of light components in the crude oil could have been stripped out from the crude oil mixture, reducing the oil rich phase volume, increasing the heavy components concentrations in the oil rich phase and leading to a more condensed oil rich phase with an increased viscosity.

\section{CORRELATIONS}

The correlation between the crude oil mixture viscosity and pressure can be described by the following equations,

$$
\begin{aligned}
& \ln \left(\eta_{\mathrm{m}}\right)=-a_{1} P+b_{1} @ P \leq P_{\min } \\
& \ln \left(\eta_{\mathrm{m}}\right)=a_{2} P+b_{2} @ P>P_{\min }
\end{aligned}
$$

where $P_{\min }$ is the pressure at which the oil mixture viscosity reaches the minimum, and $a_{i}$ and $b_{i}$ $(i=1,2)$ are fitting parameters. The values of the fitting parameters are given in Table 5. 
Alternatively, the oil mixture viscosity can be correlated with the $\mathrm{CO}_{2}$ solubility using an equation from Shu [37]:

$$
\ln \left(\eta_{\mathrm{m}}\right)=X_{\mathrm{o}} \ln \left(\eta_{\mathrm{o}}\right)+X_{\mathrm{s}} \ln \left(\eta_{\mathrm{s}}\right)
$$

with

$$
\begin{gathered}
X_{\mathrm{s}}=\frac{v_{\mathrm{s}}}{\alpha v_{\mathrm{o}}+v_{\mathrm{s}}} \\
X_{\mathrm{o}}=1-X_{\mathrm{s}}
\end{gathered}
$$

where $v$ is the volume fraction, and the subscripts $o$, s, and $m$ represent crude oil, $\mathrm{CO}_{2}$, and the crude oil mixture, respectively. From the solubility the amount of $\mathrm{CO}_{2}$ dissolved in the crude oil can be worked out, and thus the $\mathrm{CO}_{2}$ volume under the measurement condition. Assuming the crude oil has a constant density and the amount of crude oil in the oil rich phase is also a constant (i.e., the amount of crude oil components diffusing into the $\mathrm{CO}_{2}$ rich phase is negligible), the volume of crude oil in the mixture can be evaluated, and thus the volume fractions. The densities of the crude oil samples at ambient pressure were measured through a separated experiment. The values of the fitting parameter, $\alpha$, for the crude oil samples are also summarized in Table 5. It should be pointed out that, for the correlation, the viscosity of the original heavy crude oil was taken from the Newtonian plateau. The absolute average relative deviation of the correlation is $7.57 \%$ and Figure 11 shows the correlation fit.

\section{CONCLUSIONS}

In conclusion, the non-Newtonian behavior of the Zuata heavy crude oil was eliminated gradually as the dissolved $\mathrm{CO}_{2}$ concentration increased. When saturated with $\mathrm{CO}_{2}$, the crude oil viscosity 
initially decreased exponentially as the $\mathrm{CO}_{2}$ pressure was increased. After reaching a minimum, the viscosity then increased at a low rate with increasing $\mathrm{CO}_{2}$ pressure. Furthermore, the results of the view cell experiment show that $\mathrm{CO}_{2}$ dissolution caused the undiluted oil to swell as expected. However, after diluting the crude with $10 \mathrm{wt} \%$ toluene, the rate of swelling was initially greater but a maximum was observed in the oil-rich phase volume at around the pressure where the $\mathrm{CO}_{2}$ solubility started to plateau. Thereafter the oil-rich phase shrank as pressure increased. However, a second liquid phase appeared in the more diluted crude oil (30 wt\% toluene) at pressures above 100 bar. Finally, the $\mathrm{CO}_{2}$ solubility was inversely correlated to the mixture viscosity. 


\section{FIGURES}

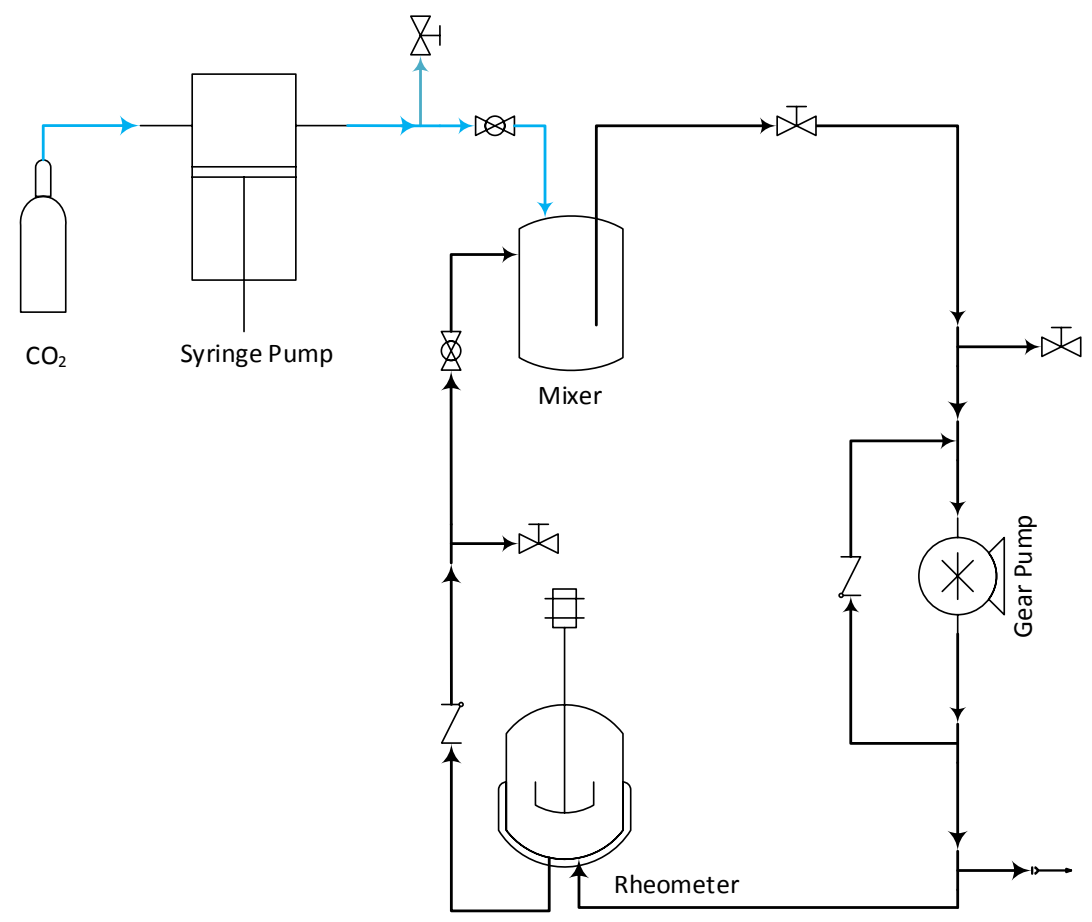

Figure 1. The scheme of the circulation system to measure the viscosity of $\mathrm{CO}_{2}$ saturated crude oils. The blue line represents $\mathrm{CO}_{2}$ flow and the black line the crude oil mixtures.

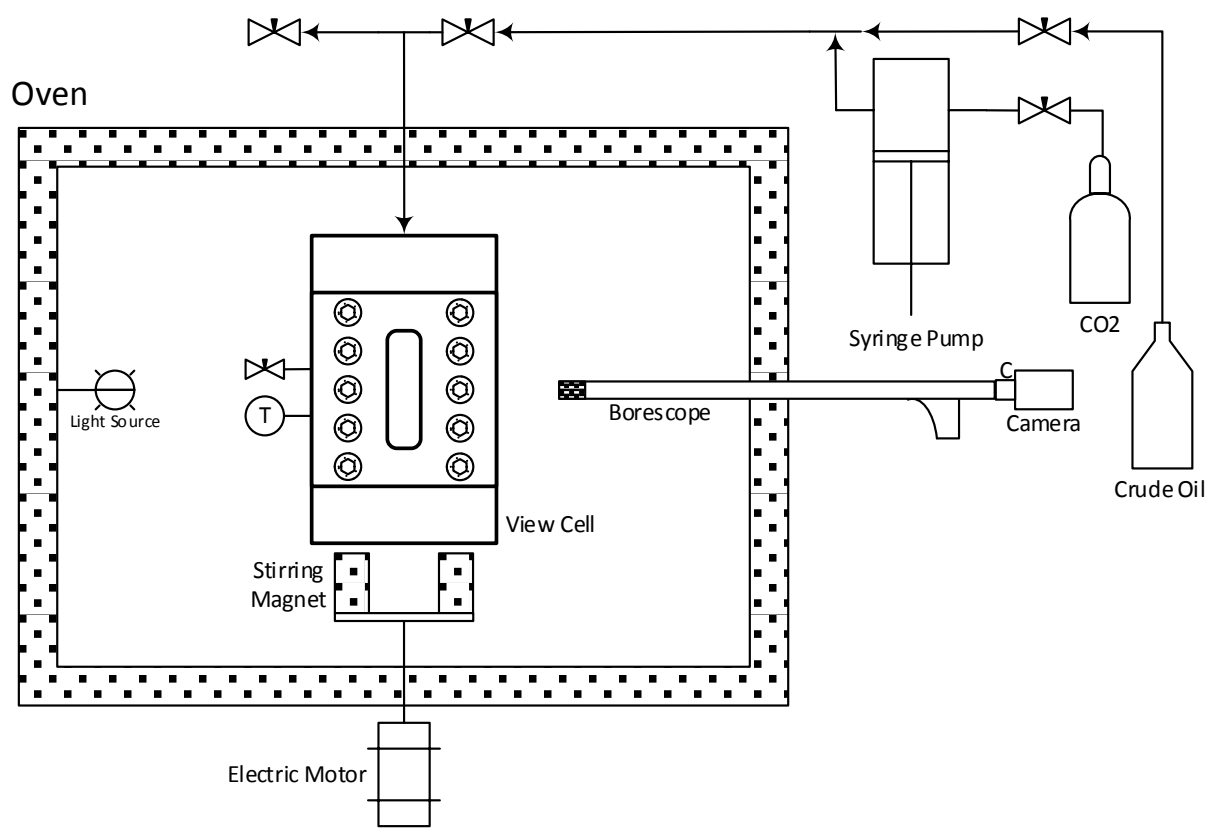

Figure 2. Scheme of the view cell system. 


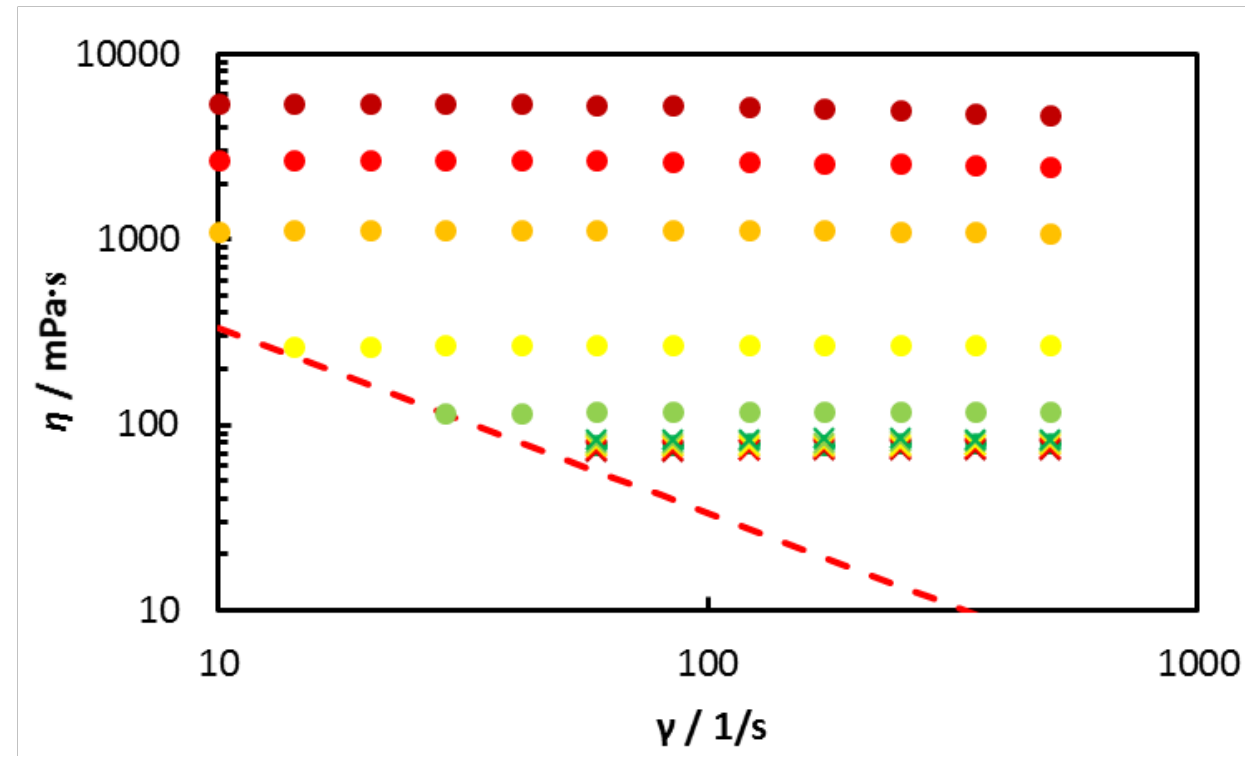

Figure 3. Viscosity measurement for the original heavy crude oil with $\mathrm{CO}_{2}$ at $50{ }^{\circ} \mathrm{C}$ and various shear rates. --, lower shear rate limit; $\odot$, ambient pressure; $\odot, 20$ bar; $\odot, 40$ bar;, 60 bar; $\odot, 80$ bar; $\odot, 100$ bar; $\times, 120$ bar; $\times, 140$ bar; $\times$, 160 bar; $\times 180$ bar; $\times, 200$ bar; $\times, 220$ bar.

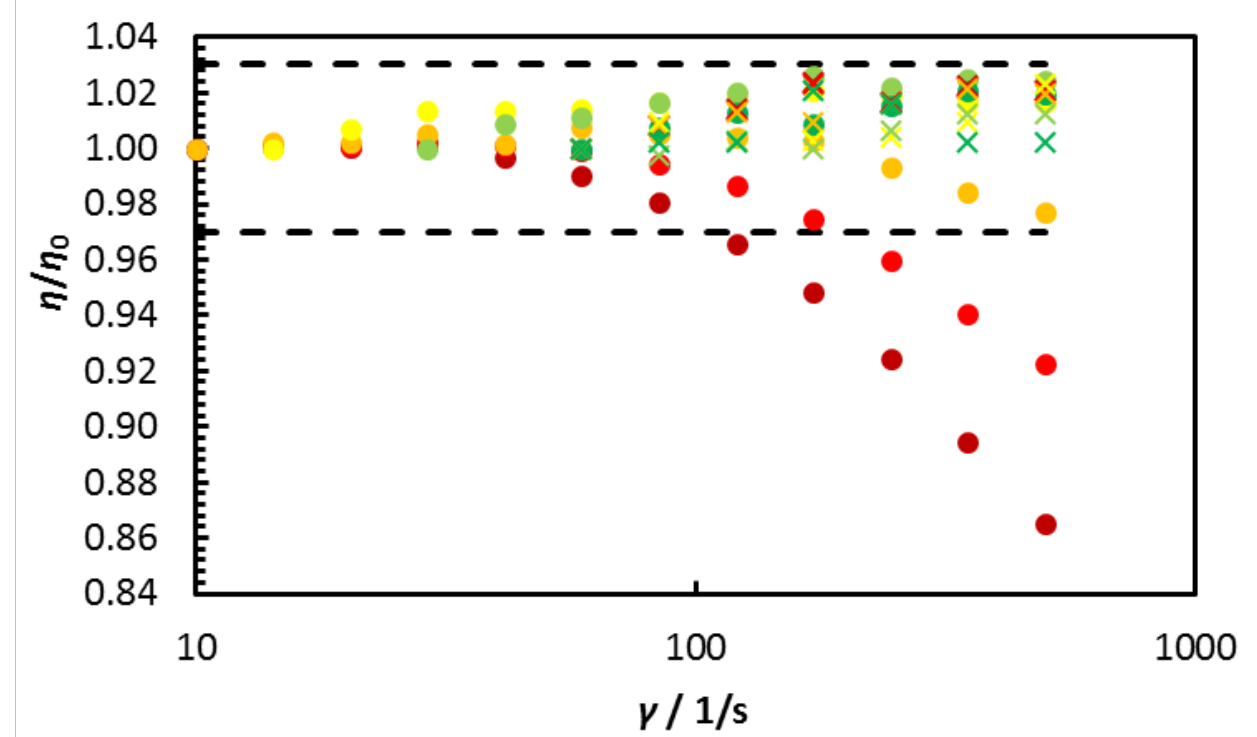

Figure 4. The relative viscosity for the original crude oil with $\mathrm{CO}_{2}$ at $50{ }^{\circ} \mathrm{C}$ and various shear rates. -- , measurement fluctuation range; $\odot$, ambient pressure; $\odot, 20$ bar; $\odot, 40$ bar; $\odot 60$ bar; $\odot, 80$ bar; $\odot, 100$ bar; $\times, 120$ bar; $\times, 140$ bar; $\times, 160$ bar; $\times, 180$ bar; $\times, 200$ bar; $\times, 220$ bar. 


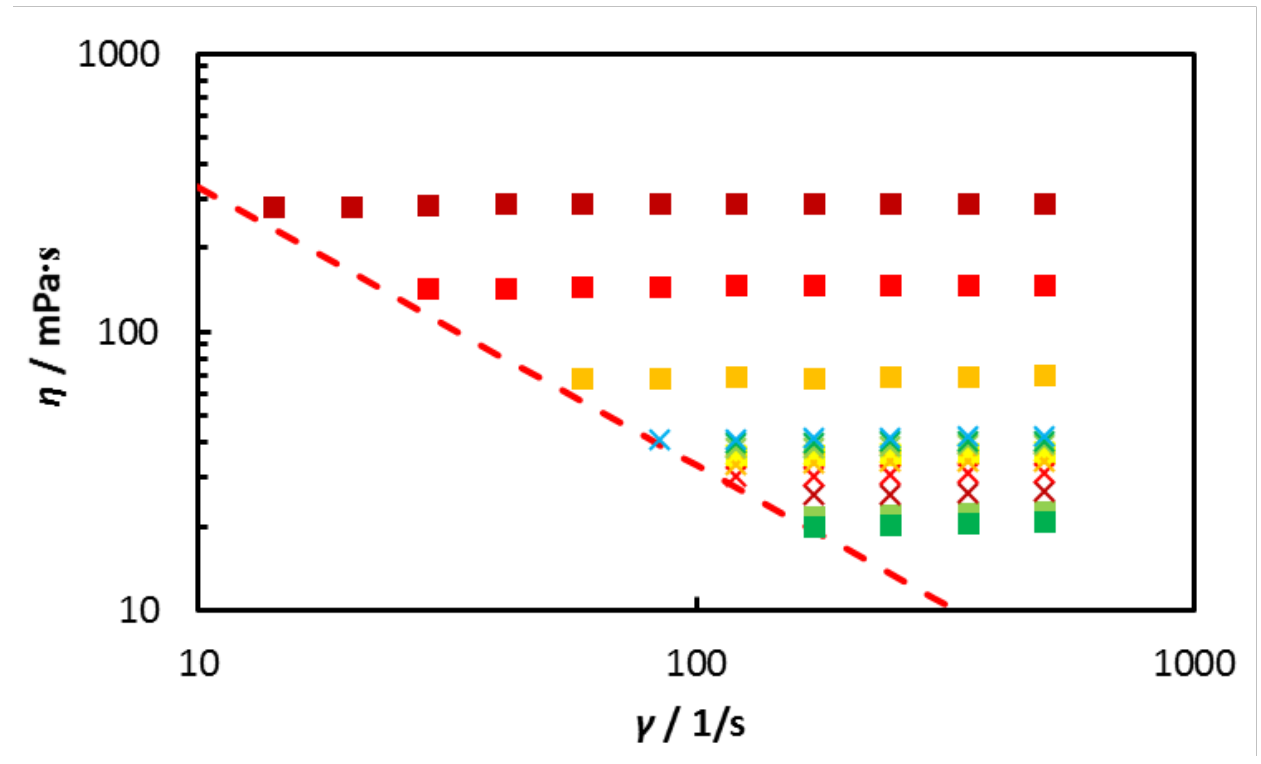

Figure 5. Viscosity measurement for diluted crude oil 1 with $\mathrm{CO}_{2}$ at $50{ }^{\circ} \mathrm{C}$ and various shear rates. - -, lower shear rate limit; $\square$, ambient pressure; $\square, 20$ bar; $\square, 40$ bar; $\square, 60$ bar; $\square, 80$ bar; $\square, 90$ bar; $\times, 100$ bar; $\times, 120$ bar; $\times, 140$ bar; $\times$, 160 bar; $\times, 180$ bar; $\times, 200$ bar; $\times, 220$ bar.

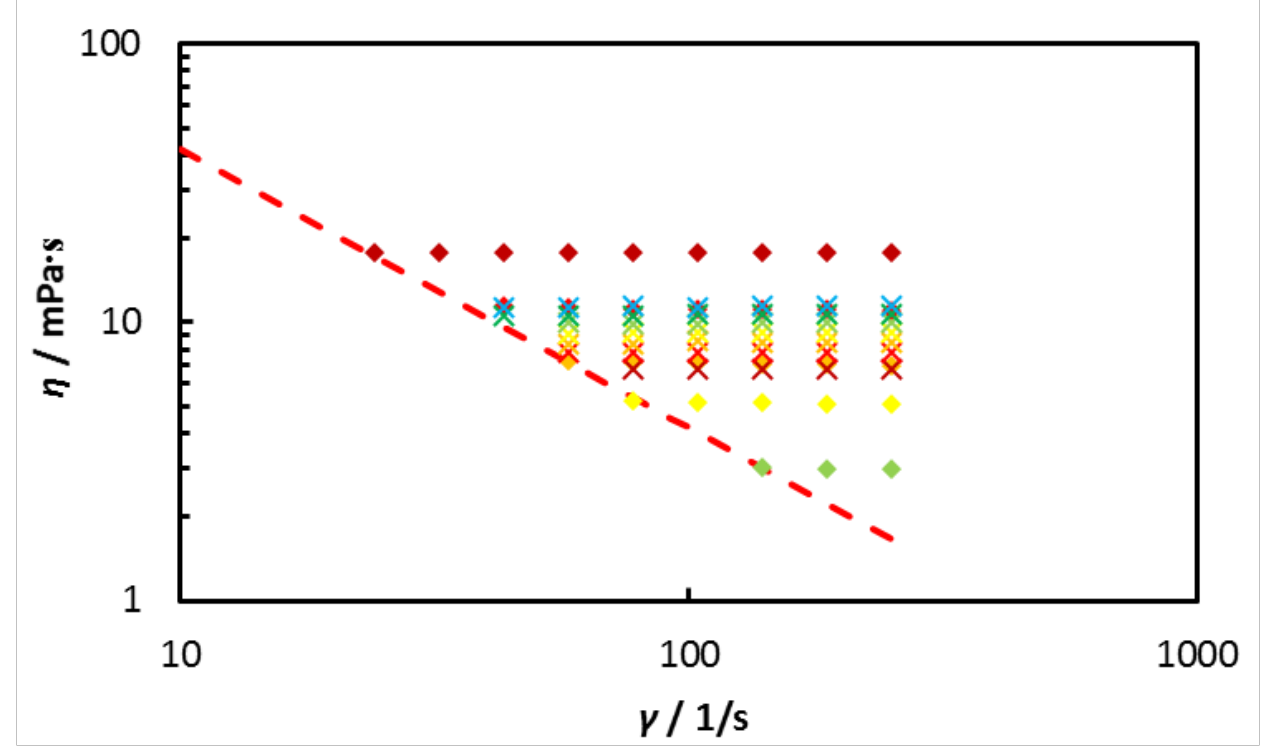

Figure 6. Viscosity measurement for diluted crude oil 2 with $\mathrm{CO}_{2}$ at $50{ }^{\circ} \mathrm{C}$ and various shear rates in the second run. - -, lower shear rate limit; $\diamond$, ambient pressure; $\diamond, 20$ bar; $\diamond, 40$ bar;, 60 bar; $\diamond, 80$ bar; $\times, 100$ bar; $\times, 120$ bar; $\times, 140$ bar; 160 bar; $\times, 180$ bar; $\times, 200$ bar; $\times, 220$ bar. 


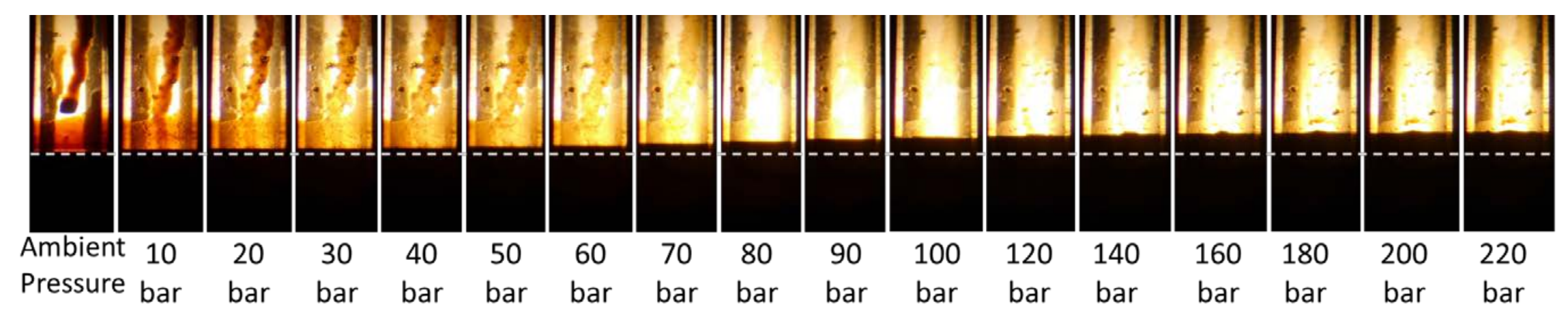

Figure 7. Phase behavior at various pressures of $\mathrm{CO}_{2}$ mixed with the original heavy crude oil at $50^{\circ} \mathrm{C}$. The while dash line marks the level of the crude oil at 1 bar.

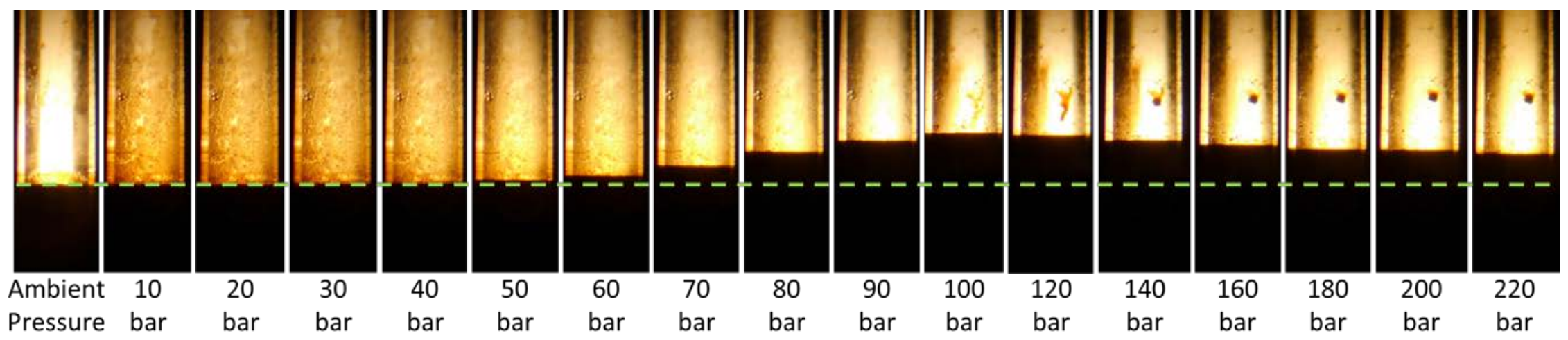

Figure 8. Phase behavior at various pressures of $\mathrm{CO}_{2}$ mixed with diluted crude oil 1 at $50{ }^{\circ} \mathrm{C}$. The green dash line marks the level of the crude oil at 1 bar. 


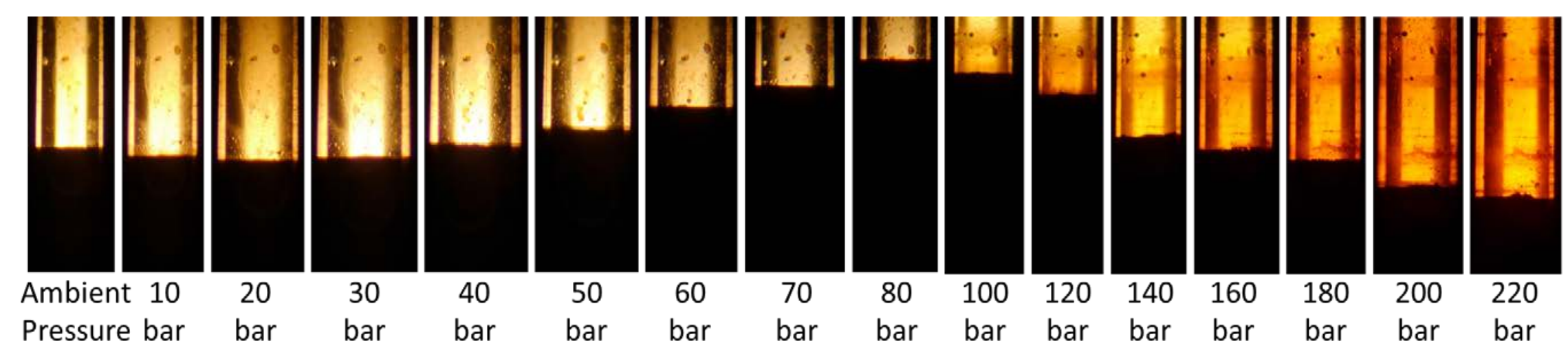

Figure 9. Phase behavior at various pressures of $\mathrm{CO}_{2}$ mixed with diluted crude oil 2 at $50{ }^{\circ} \mathrm{C}$. 


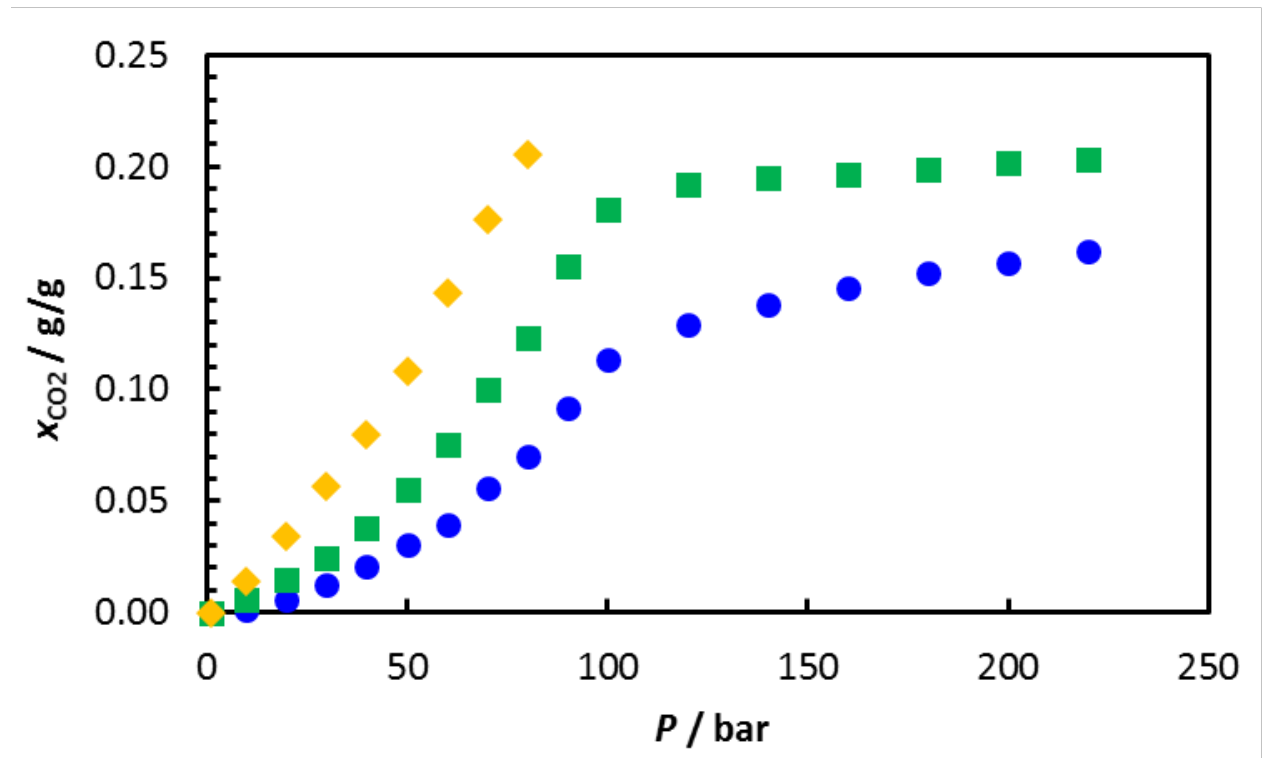

Figure 10. The solubility of $\mathrm{CO}_{2}$ in the diluted crude oils and original crude oil at $50{ }^{\circ} \mathrm{C}$ and pressure up to 220 bar. $\bigcirc$, original heavy crude oil; $\square$, diluted crude oil $1(10 \mathrm{wt} \%$ toluene); $\vee$, diluted crude oil 2 (30 wt \% toluene).

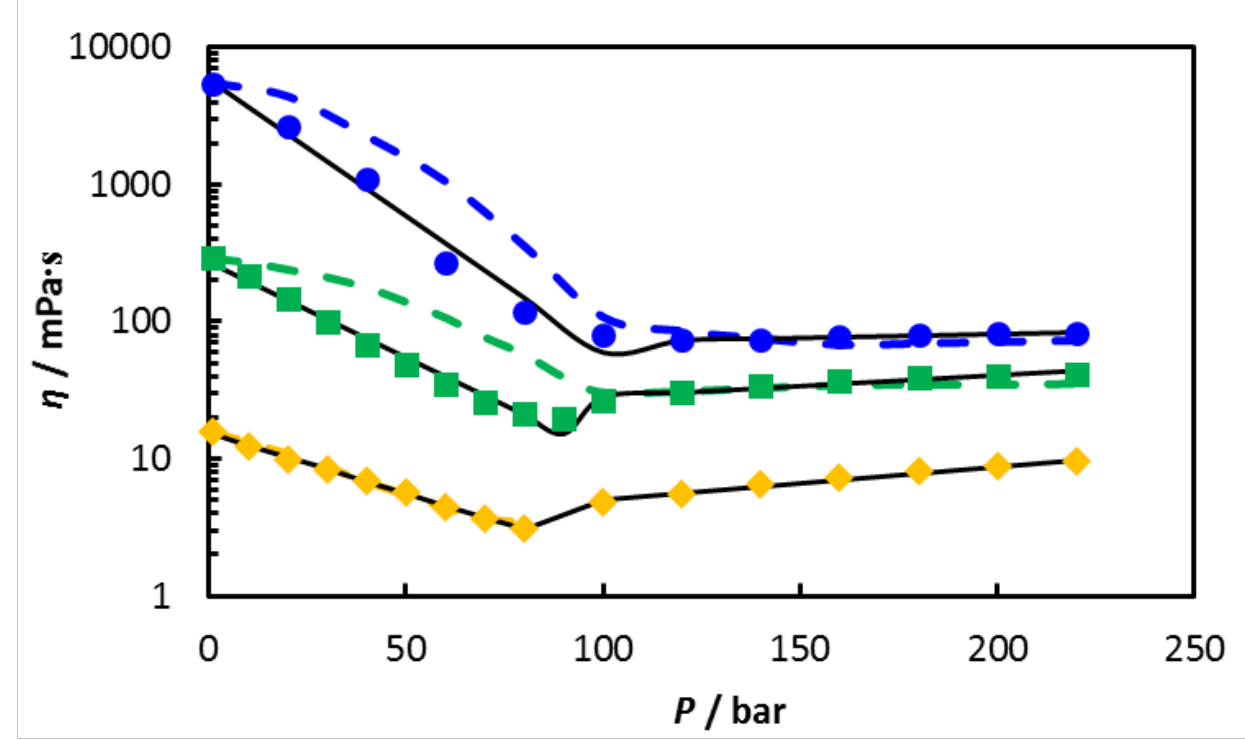

Figure 11. The comparison between the viscosity correlation results and measurements. -, correlation by Equation (13) and (14). 9 , original heavy crude oil; - - correlation by Equation (15) for original heavy crude oil; $\square$, diluted crude oil 1 (10 wt\% toluene); - -, correlation by Equation (15) for diluted crude oil 1; $>$, diluted crude oil 2 (with 30 wt\% toluene); - - correlation by Equation (15) for diluted crude oil 2 (30 wt\% toluene). 


\section{TABLES.}

Table 1. The rheology experiment data of the original crude oil saturated with $\mathrm{CO}_{2}$ at temperature of $50{ }^{\circ} \mathrm{C}$.

\begin{tabular}{ccccccccccccc}
\hline$P /$ bar & Ambient & 20 & 40 & 60 & 80 & 100 & 120 & 140 & 160 & 180 & 200 & 220 \\
\hline$\gamma / \mathrm{s}^{-1}$ & & & & \multicolumn{7}{c}{$\eta / \mathrm{mPa} \cdot \mathrm{s}$} \\
10.0 & 5380 & 2650 & 1110 & & & & & & & & & \\
14.3 & 5382 & 2652 & 1112 & 264.2 & & & & & & & & \\
20.4 & 5382 & 2652 & 1112 & 266.0 & & & & & & & & \\
29.1 & 5386 & 2656 & 1116 & 267.7 & 115.7 & & & & & & & \\
41.5 & 5362 & 2652 & 1112 & 267.7 & 116.7 & & & & & & & \\
59.2 & 5328 & 2648 & 1118 & 268.0 & 117.0 & 78.00 & 72.00 & 73.00 & 76.00 & 77.40 & 80.40 & 83.30 \\
84.5 & 5276 & 2636 & 1116 & 268.6 & 117.6 & 78.60 & 72.60 & 73.60 & 76.60 & 78.10 & 80.20 & 83.50 \\
121 & 5194 & 2614 & 1114 & 269.0 & 118.0 & 79.00 & 73.00 & 74.00 & 77.00 & 77.60 & 80.60 & 83.50 \\
172 & 5103 & 2583 & 1113 & 269.7 & 118.7 & 78.70 & 73.70 & 74.70 & 76.70 & 77.60 & 80.40 & 85.00 \\
246 & 4972 & 2542 & 1102 & 269.2 & 118.2 & 79.20 & 73.20 & 74.20 & 77.20 & 77.70 & 80.90 & 84.60 \\
350 & 4813 & 2493 & 1093 & 268.6 & 118.6 & 79.60 & 73.60 & 74.60 & 77.60 & 78.10 & 81.40 & 83.50 \\
500 & 4655 & 2445 & 1085 & 268.5 & 118.5 & 79.50 & 73.50 & 74.50 & 77.50 & 79.20 & 81.40 & 83.50 \\
\hline
\end{tabular}


Table 2. The rheology experiment data of diluted crude oil 1 saturated with $\mathrm{CO}_{2}$ at temperature of $50{ }^{\circ} \mathrm{C}$.

\begin{tabular}{|c|c|c|c|c|c|c|c|c|c|c|c|c|c|}
\hline$P$ / bar & Ambient & 20 & 40 & 60 & 80 & 90 & 100 & 120 & 140 & 160 & 180 & 200 & 220 \\
\hline$\gamma / 1 / \mathrm{s}$ & \multicolumn{13}{|c|}{$\eta / \mathrm{mPa} \cdot \mathrm{s}$} \\
\hline 14.2 & 282.0 & & & & & & & & & & & & \\
\hline 20.3 & 282.7 & & & & & & & & & & & & \\
\hline 29 & 285.9 & 143.9 & & & & & & & & & & & \\
\hline 41.4 & 288.4 & 144.4 & & & & & & & & & & & \\
\hline 59.1 & 289.2 & 146.2 & 68.10 & & & & & & & & & & \\
\hline 84.4 & 290.5 & 146.5 & 68.50 & & & & & & & & & & 41.20 \\
\hline 120 & 290.2 & 147.2 & 69.20 & 35.60 & & & & 30.10 & 33.40 & 36.20 & 38.20 & 39.80 & 41.20 \\
\hline 172 & 290.7 & 147.7 & 68.70 & 36.00 & 21.90 & 20.10 & 26.00 & 30.40 & 33.80 & 36.40 & 38.50 & 40.10 & 41.50 \\
\hline 245 & 290.6 & 147.6 & 69.60 & 36.20 & 22.10 & 20.40 & 26.20 & 30.70 & 34.10 & 36.60 & 38.80 & 40.20 & 41.80 \\
\hline 350 & 289.5 & 148.5 & 69.50 & 36.50 & 22.40 & 20.70 & 26.50 & 31.00 & 34.30 & 36.90 & 39.10 & 40.50 & 42.00 \\
\hline 500 & 288.2 & 148.2 & 70.20 & 36.70 & 22.60 & 20.80 & 26.70 & 31.10 & 34.40 & 37.00 & 39.20 & 40.60 & 42.20 \\
\hline
\end{tabular}


Table 3. The rheology experiment data of diluted crude oil 2 saturated with $\mathrm{CO}_{2}$ at temperature of $50{ }^{\circ} \mathrm{C}$.

\begin{tabular}{|c|c|c|c|c|c|c|c|c|c|c|c|c|}
\hline$P /$ bar & Ambient & 20 & 40 & 60 & 80 & 100 & 120 & 140 & 160 & 180 & 200 & 220 \\
\hline$\gamma / \mathrm{s}^{-1}$ & \multicolumn{12}{|c|}{$\eta / \mathrm{mPa} \cdot \mathrm{s}$} \\
\hline 24.06 & 17.89 & & & & & & & & & & & \\
\hline 32.24 & 17.83 & & & & & & & & & & & \\
\hline 43.20 & 17.82 & 11.47 & & & & & & & & & 10.49 & 11.25 \\
\hline 57.89 & 17.79 & 11.32 & 7.27 & & & & 7.83 & 8.333 & 9.054 & 9.952 & 10.58 & 11.32 \\
\hline 77.57 & 17.70 & 11.19 & 7.21 & 5.201 & & 6.833 & 7.752 & 8.365 & 9.154 & 9.905 & 10.62 & 11.39 \\
\hline 103.9 & 17.77 & 11.18 & 7.13 & 5.174 & & 6.823 & 7.813 & 8.589 & 9.191 & 9.913 & 10.65 & 11.36 \\
\hline 139.3 & 17.70 & 11.11 & 7.04 & 5.135 & 3.025 & 6.823 & 7.801 & 8.462 & 9.207 & 9.949 & 10.65 & 11.49 \\
\hline 186.6 & 17.72 & 11.09 & 7.07 & 5.095 & 2.982 & 6.833 & 7.803 & 8.48 & 9.205 & 9.934 & 10.73 & 11.44 \\
\hline 250.0 & 17.72 & 11.04 & 7.00 & 5.065 & 2.981 & 6.828 & 7.762 & 8.494 & 9.193 & 9.978 & 10.69 & 11.45 \\
\hline
\end{tabular}


Table 4. Composition of the crude oil samples studied

\begin{tabular}{ll}
\hline \multicolumn{1}{c}{ Sample } & \multicolumn{1}{c}{ Composition } \\
\hline \hline original heavy crude oil & $100 \mathrm{wt} \%$ Zuata crude oil \\
diluted crude oil 1 & $90 \mathrm{wt} \%$ Zuata crude oil + 10 wt\% toluene \\
diluted crude oil 2 & $70 \mathrm{wt} \%$ Zuata crude oil + 30 wt\% toluene \\
\hline
\end{tabular}

Table 5. The value of the fitting parameters in Equation (13), (14) and (15)

\begin{tabular}{l|c|ccccc}
\hline \multicolumn{1}{c|}{ Component } & \multirow{2}{*}{$T /{ }^{\circ} \mathrm{C}$} & \multicolumn{5}{c}{$\mathrm{CO}_{2}$ Mixture } \\
& & $a_{1}$ & $b_{1}$ & $a_{2}$ & $b_{2}$ & $\alpha$ \\
\hline \hline Zuata Crude Oil & 50 & 0.0458 & 8.6680 & 0.0013 & 4.1340 & 155.331 \\
Diluted Crude Oil 1 & 50 & 0.0320 & 5.6021 & 0.0037 & 2.9730 & 368.526 \\
Diluted Crude Oil 2 & 50 & 0.0204 & 2.7372 & 0.0056 & 1.0518 & 284.190 \\
\hline
\end{tabular}

\section{AUTHOR INFORMATION}

\section{Corresponding Author}

John P. Crawshaw. Email: j.crawshaw@imperial.ac.uk

\section{Notes}

The authors declare no competing financial interest.

\section{ACKNOWLEDGMENTS}

The authors gratefully acknowledge funding from the Qatar Carbonates and Carbon Storage Research Centre (QCCSRC), provided jointly by Qatar Petroleum, Shell, and Qatar Science and Technology Park. The authors thank Frans van den Berg (Shell Global Solutions, Amsterdam, Netherlands) for providing the crude oil sample. Alexander Wilson (Schlumberger Gould Research, Cambridge, UK) is gratefully acknowledged for making the view cell available. 


\section{REFERENCES}

1. Yu, K.M., et al., Recent advances in CO2 capture and utilization. ChemSusChem, 2008. 1(11): p. 893-9.

2. McCoy, S., Carbon Capture and Storage: Legal and Regulatory Review. 2014, Paris: IEA.

3. Cuéllar-Franca, R.M. and A. Azapagic, Carbon capture, storage and utilisation technologies: A critical analysis and comparison of their life cycle environmental impacts. Journal of CO2 Utilization, 2015. 9: p. 82-102.

4. Chung, F.T., R.A. Jones, and H.T. Nguyen, Measurements and correlations of the physical properties of CO2/heavy-crude-oil mixtures. SPE Reservoir Eng, 1988. 3(3): p. 822-828.

5. Jacobs, F.A., J.K. Donnelly, and J. Stanislav, Viiscosity of Gas-saturated Bitumen. Journal of Canadian Petroleum Technology, 2013. 19(04).

6. Sayegh, S.G., et al., Phase-Behavior and Physical-Properties of Lindbergh Heavy Oil/Co2 Mixtures. Journal of Canadian Petroleum Technology, 1990. 29(6): p. 31-39.

7. Kokal, S.L. and S.G. Sayegh, Phase behavior and physical properties of CO2-saturated heavy oil and its constitutive fractions: Experimental data and correlations. Journal of Petroleum Science and Engineering, 1993. 9(4): p. 289-302.

8. Quail, B., G.A. Hill, and K.N. Jha, Correlations of Viscosity, Gas Solubility, and Density for Saskatchewan Heavy Oils. Industrial \& Engineering Chemistry Research, 1988. 27(3): p. 519-523.

9. Badamchi-Zadeh, A., et al., Phase Behaviour and Physical Property Measurements for VAPEX Solvents: Part II. Propane, Carbon Dioxide and Athabasca Bitumen. Journal of Canadian Petroleum Technology, 2009. 48(3): p. 57-65.

10. Lansangan, R.M., Viscosity, Density, and Composition Measurements of Co2/West Texas Oil Systems. Spe Reservoir Engineering, 1993. 8(3): p. 175-182.

11. Jha, K.N., A Laboratory Study of Heavy Oil-Recovery with Carbon-Dioxide. Journal of Canadian Petroleum Technology, 1986. 25(2): p. 54-63.

12. Li, H.Z., S.X. Zheng, and D.Y. Yang, Enhanced Swelling Effect and Viscosity. Reduction of Solvent(s)/CO2/Heavy-Oil Systems. Spe Journal, 2013. 18(4): p. 695-707.

13. Orr, F.M., A.D. Yu, and C.L. Lien, Phase-Behavior of Co2 and Crude-Oil in LowTemperature Reservoirs. Society of Petroleum Engineers Journal, 1981. 21(4): p. 480492.

14. Orr, F.M. and C.M. Jensen, Interpretation of Pressure-Composition Phase-Diagrams for Co2 Crude-Oil Systems. Society of Petroleum Engineers Journal, 1984. 24(5): p. 485497.

15. Liu, Z.M., et al., Phase equilibria of the CO2-Jiangsu crude oil system and precipitation of heavy components induced by supercritical CO2. Journal of Supercritical Fluids, 1999. 16(1): p. 27-31.

16. Kariznovi, M., H. Nourozieh, and J. Abedi, Experimental apparatus for phase behavior study of solvent-bitumen systems: A critical review and design of a new apparatus. Fuel, 2011. 90(2): p. 536-546. 
17. Argillier, J.F., C. Coustet, and I. Henaut, Heavy Oil Rheology as a Function of Asphaltene and Resin Content and Temperature. Society of Petroleum Engineers.

18. Hasan, S.W., M.T. Ghannam, and N. Esmail, Heavy crude oil viscosity reduction and rheology for pipeline transportation. Fuel, 2010. 89(5): p. 1095-1100.

19. Martínez-Palou, R., et al., Transportation of heavy and extra-heavy crude oil by pipeline: A review. Journal of Petroleum Science and Engineering, 2011. 75(3-4): p. 274-282.

20. Ghannam, M.T., et al., Rheological properties of heavy \& light crude oil mixtures for improving flowability. Journal of Petroleum Science and Engineering, 2012. 81: p. 122128.

21. Henaut, I., et al., Rheological and Structural Properties of Heavy Crude Oils in Relation With Their Asphaltenes Content. Society of Petroleum Engineers.

22. Yaghi, B.M. and A. Al-Bemani, Heavy crude oil viscosity reduction for pipeline transportation. Energy Sources, 2002. 24(2): p. 93-102.

23. Hemmingsen, P.V., et al., Emulsions of heavy crude oils. I: Influence of viscosity, temperature, and dilution. Journal of Dispersion Science and Technology, 2005. 26(5): p. 615-627.

24. Petter Rønningsen, H., Rheological behaviour of gelled, waxy North Sea crude oils. Journal of Petroleum Science and Engineering, 1992. 7(3-4): p. 177-213.

25. Behzadfar, E. and S.G. Hatzikiriakos, Rheology of bitumen: Effects of temperature, pressure, CO2 concentration and shear rate. Fuel, 2014. 116(0): p. 578-587.

26. Hu, R.E., et al., Rheology of Diluted Heavy Crude Oil Saturated with Carbon Dioxide. Energy \& Fuels, 2015. 29(5): p. 2785-2789.

27. Ku, H., Notes on the use of propagation of error formulas. Journal of Research of the National Bureau of Standards, 1966. 70(4).

28. Day, C.Y., C.J. Chang, and C.Y. Chen, Phase equilibrium of ethanol plus CO2 and acetone plus CO2 at elevated pressures. Journal of Chemical and Engineering Data, 1996. 41(4): p. 839-843.

29. Zhang, Y.P., C.L. Hyndman, and B.B. Maini, Measurement of gas diffusivity in heavy oils. Journal of Petroleum Science and Engineering, 2000. 25(1-2): p. 37-47.

30. Bird, R.B., W.E. Stewart, and E.N. Lightfoot, Transport phenomena, revised. 2007, New York: John Wiley \& Sons, Inc.

31. McManamey, W.J. and J.M. Woollen, The diffusivity of carbon dioxide in some organic liquids at $25^{\circ}$ and $50^{\circ} \mathrm{C}$. AIChE Journal, 1973. 19(3): p. 667-669.

32. Linstrom, P.J. and E. W.G. Mallard, NIST Chemistry WebBook, NIST Standard Reference Database Number 69. 2014: National Institute of Standards and Technology.

33. Miller, J.S. and R.A. Jones. SPE/DOE 9789. in SPE/DOE Symposium on Enhanced Oil Recovery. 1981. Society of Petroleum Engineers.

34. Bui, L.H., J.-S. Tsau, and G.P. Willhite, Laboratory Investigations of CO2 Near Miscible Application in Arbuckle Reservoir. Society of Petroleum Engineers.

35. Tsau, J.-S., L.H. Bui, and G.P. Willhite, Swelling/Extraction Test of a Small Sample Size for Phase Behavior Study. Society of Petroleum Engineers.

36. Abedini, A., N. Mosavat, and F. Torabi, Determination of Minimum Miscibility Pressure of Crude Oil-CO2 System by Oil Swelling/Extraction Test. Energy Technology, 2014. 2(5): p. 431-439.

37. Shu, W.R., A Viscosity Correlation for Mixtures of Heavy Oil, Bitumen, and Petroleum Fractions. Society of Petroleum Engineers Journal, 1984. 24(3): p. 277-282. 
